\title{
ANALISIS JEMBATAN BETON PRATEGANG BOX GIRDER DENGAN METODE BALANCED CANTILEVER
}

\author{
Willy Kosim ${ }^{1}$ dan F.X. Supartono ${ }^{2}$ \\ ${ }^{1}$ Program Studi Sarjana Teknik Sipil, Universitas Tarumanagara, Jl. Letjen S. Parman No.1 Jakarta \\ willy.325160025@stu.untar.ac.id \\ ${ }^{2}$ Program Studi Sarjana Teknik Sipil, Universitas Tarumanagara, Jl. Letjen S. Parman No.1 Jakarta \\ fxsupartono@gmail.com
}

Masuk: 17-01-2020, revisi: 04-03-2020, diterima untuk diterbitkan: 05-03-2020

\begin{abstract}
Indonesia is a country that has a large population, causing severe traffic jam. Therefore, the bridge is an important part in Indonesia to overcome the traffic jam. The choice of method is very important in bridge construction, so it does not interfere with the routines of the people. Bridges using the balanced cantilever method become the choice that is often used in bridge construction, because this construction method does not require direct contact with the ground. However, prestressed concrete bridge with this construction method requires more sophisticated technology and adequate work. The girder used is a box girder because the torque resistance is quite high and its self weight relatively lighter. Box girders in the balanced cantilever method can also be made to vary in height and become smaller at the end of the cantilever, therefore reducing the weight due to self weight. At this writing, stress analysis during the construction period and after construction is complete, the box girder prestressed concrete bridges using the balanced cantilever method will be carried out with the Midas Civil program in accordance with the loading standards in SNI 1725: 2016, ASTM in the use of materials, and CEB-FIP in determining creep and shrinkage.
\end{abstract}

Keywords: Balanced Cantilever; Box girder; Prestressed Concrete; Midas Civil.

\begin{abstract}
ABSTRAK
Indonesia merupakan negara yang memiliki jumlah penduduk yang banyak, sehingga menimbulkan kemacetan lalu lintas yang sangat parah. Oleh karena itu, jembatan merupakan bagian penting di Indonesia untuk mengatasi kemacetan tersebut. Pemilihan metode menjadi sangat penting dalam konstruksi jembatan agar tidak mengganggu rutinitas dari masyarakat. Jembatan dengan metode balanced cantilever menjadi pilihan yang sering digunakan dalam pembangunan jembatan, karena metode konstruksi ini tidak memerlukan kontak langsung dengan tanah. Namun, jembatan beton prategang dengan metode konstruksi ini memerlukan teknologi yang lebih canggih dan kemampuan kerja yang memadai. Gelagar yang digunakan adalah box girder karena ketahanan torsi yang cukup tinggi dan berat sendiri yang relatif lebih ringan. Box girder pada metode balanced cantilever juga dapat dibuat bervariasi tingginya dan mengecil pada ujung kantilever, sehingga mengurangi berat akibat diri sendiri. Pada penulisan ini, analisis tegangan selama masa konstruksi dan setelah konstruksi selesai, jembatan beton prategang box girder dengan metode balanced cantilever akan dilakukan dengan program Midas Civil sesuai dengan standar pembebanan pada SNI 1725 : 2016, ASTM dalam penggunaan material, dan CEB-FIP dalam menentukan creep dan shrinkage.
\end{abstract}

Kata kunci: Metode Balanced Cantilever; Box girder; Beton Prategang; Midas Civil.

\section{PENDAHULUAN}

Indonesia adalah negara kepulauan yang terdiri dari banyak pulau-pulau yang terpisah oleh sungai, danau, dan laut. Maka dari itu, perkembangan teknologi pembangunan jembatan sangat diperlukan mengingat pembangunan jembatan bentang panjang yang akan menyeberangi sungai-sungai lebar dan yang akan menghubungkan pulau-pulau di nusantara sangat dibutuhkan. Oleh karena itu, diperlukan penguasaan teknologi jembatan baik dari aspek peralatan, material maupun perencanaannnya mutlak dibutuhkan. Dalam melakukan suatu perencanan jembatan seorang perencana disarankan untuk menggunakan dan menguasai teknologi material yang mempunyai nilai efisiensi tinggi, kedap air, dan kuat menahan gaya-gaya yang bekerja di jembatan.

Jembatan adalah suatu struktur konstruksi yang berfungsi untuk menghubungkan dua bagian jalan yang terputus oleh adanya rintangan-rintangan seperti jurang yang dalam, alur sungai saluran irigasi, kereta api dan dapat juga 
digunakan untuk daerah yang selalu mengalami permasalahan kemacetan lalu lintas. Permasalahan kemacetan lalu lintas di Indonesia cukup parah karena Indonesia menduduki urutan keempat negara dengan jumlah penduduk terbesar di dunia, dan setiap tahunnya penduduk Indonesia semakin bertambah disertai dengan meningkatnya daya beli masyarakat terhadap kendaraan bermotor.

Akibat dari kenaikan jumlah kendaraan ini, maka timbul masalah kemacetan di daerah-daerah tertentu karena infrastruktur jalanan yang belum memadai. Pada pemerintahan dibawah kepemimpinan Presiden Joko Widodo, pembangunan infrastruktur menjadi prioritas pembangunan nasional. Salah satu bentuk infrastruktur jembatan yang sering ditemukan adalah jembatan layang ( fly over ).

Jenis jembatan yang paling sering ditemukan adalah jembatan beton prategang karena mempunyai efisiensi yang tinggi dan mampu menahan gaya yang bekerja pada jembatan dengan baik. Jembatan beton prategang atau yang dikenal dengan prestressed concrete bridge merupakan salah satu jenis jembatan dengan material konstruksi beton prategang atau beton yang berisi kabel baja dengan tujuan untuk memberikan tegangan berupa tegangan tekan tambahan terhadap beton agar dapat megurangi lendutan akibat beban kerja. Dalam hal ini, beton prategang sebagai solusi untuk mengatasi besarnya tegangan tarik yang timbul pada struktur beton khususnya pada struktur dengan bentang yang besar.

\section{Metode konstruksi}

Dalam konstruksi jembatan beton prategang terdapat beberapa metode pelaksanaan konstruksi jembatan yang digunakan pada umumnya di Indonesia seperti MSS ( Movable Scaffolding System ), ILM ( Increamental Launching Method ), Balanced Cantilever dengan Form Traveller, dan Cable Stayed. Masing - masing dari metode pelaksanaan tersebut terdapat kelebihan dan kekurangan yang harus disesuaikan dengan kondisi lapangan. Pemilihan metode pelaksanaan sangat penting karena pemilihan metode tersebut akan berdampak kepada lamanya proses konstruksi, selain itu juga berpengaruh pada jumlah strands yang akan digunakan pada tendon jembatan yang akan berdampak pada biaya konstruksi.

\section{Balanced cantilever dan box girder}

Untuk beberapa tahun terakhir ini, perencanaan struktur jembatan jembatan beton prategang yang paling sering ditemukan adalah jembatan dengan menggunakan box girder dengan prinsip beton prategang dan menggunakan metode balanced cantilever. Metode balanced cantilever adalah metode konstruksi yang memanfaatkan efek keseimbangan kantilever yang bertumpu pada pier. Pier yang akan menopang segmen demi segmen yang disusun sebagai kantilever dikedua sisinya dengan bantuan strand yang kemudian distressing agar seimbang dengan koordinat vertikal dek di sepanjang kantilever harus berada di dalam nilai toleransi yang diterima (Hernandez, Ouro, dan Romera 2014), sehingga metode balanced cantilever sangat cocok digunakan pada lokasi yang sulit seperti di jurang, di atas sungai dengan aliran yang deras, di atas rel kereta api karena jembatan dapat dibangun tanpa ada kontak dengan tanah, dan tanpa menggunakan bantuan sokongan lain seperti perancah/Shoaring.

Dalam mendesain jembatan tipe ini perlu dilakukan analisa jembatan secara menyeluruh dan konstruksi bertahap khususnya dalam pelaksanaan konstruksi jembatan. Dimana dalam pelaksanaan konstruksi jembatan setiap tahapan konstruksi, besarnya gaya-gaya dalam, tidak boleh melampaui kapasitas penampang (Irpan, 2011).

Dalam pembangunan jembatan menggunakan metode balanced cantilever, gelagar yang umum digunakan adalah box girder karena memiliki keunggulan yang tahan terhadap torsi dan dapat mengurangi beban sendiri dari jembatan karena terdapat void pada bagian tengah dari gelagar itu sendiri. Metode balanced cantilever juga mendukung adanya pengurangan tinggi dari box girder yang bisa mengurangi beban sendiri dari jembatan itu sendiri. Metode stressing pada metode ini akan lebih baik menggunakan stressing dua arah karena menghasilkan kehilangan prategang yang lebih kecil dibandingkan stressing 1 arah (Rizkia, 2017). Ilustrasi dalam pembangunan jembatan beton prategang box girder dengan metode balanced cantilever dapat dilihat di Gambar 1. 


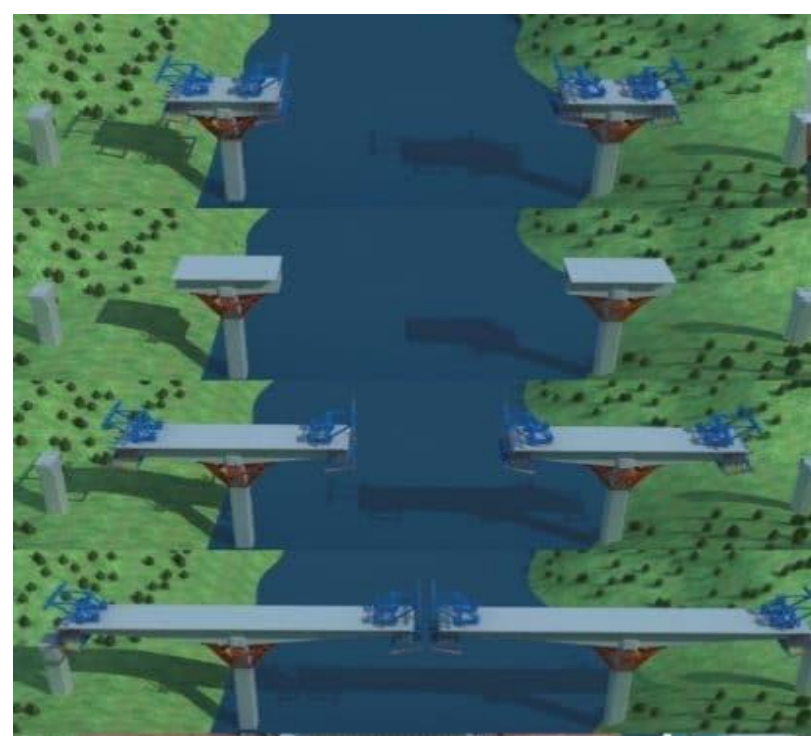

Gambar 1. Ilustrasi balanced cantilever

\section{Pembebanan dan tegangan izin}

Pembebanan dilakukan berdasarkan SNI 1725 : 2016 dengan memperhitungkan SDL, BTR, dan BGT. Berikut detail dari pembebanan yang dilakukan :

- Beban SDL yang digunakan adalah lapisan permukaan beton aspal yaitu dengan berat isi $22 \mathrm{KN} / \mathrm{m} 3 \mathrm{sesuai}$ pada tabel 4.1. Tebal aspal di asumsikan $3 \mathrm{~cm}$ dengan lebar jalan dan trotoar sebesar $9 \mathrm{~m}$. Sehingga beban SDL yang dimasukkan adalah $22 \mathrm{KN} / \mathrm{m} 3$ x 0,03 $\mathrm{m}$ x $9 \mathrm{~m}=5,94 \mathrm{KN} / \mathrm{m}$.

- $\quad$ Beban BTR yang digunakan adalah panjang jembatan yang lebih dari 30m, sehinggu beban BTR adalah 9 $\mathrm{x}(0,5+15 / 200)=5,175 \mathrm{KN} / \mathrm{m} 2 \times 9 \mathrm{~m}=46,575 \mathrm{KN} / \mathrm{m}$.

- Besarnya beban BGT adalah $49 \mathrm{KN} / \mathrm{m} \times 9 \mathrm{~m}=441 \mathrm{KN}$ ( beban terpusat ).

Hasil tegangan dari pembebanan pada jembatan akan diberi batasan berdasarkan SNI 2847:2013 dengan f'c =60. Berikut detail dari tegangan izin yang dijadikan acuan.

- Keadaan awal sebelum kehilangan prategang

$\begin{array}{llll}\text { Tegangan izin tekan } & : 0,6 \mathrm{f}^{\prime} \mathrm{ci} & =0,6 \times 48 & =28,8 \mathrm{MPa} \\ \text { Tegangan izin tarik } & : 0,5 . \sqrt{ }\left(\mathrm{f}^{\prime} \mathrm{ci}\right) & =0,5 \times \sqrt{4} & =3,46 \mathrm{MPa}\end{array}$

- Keadaan akhir setelah kehilangan prategang

$\begin{array}{llll}\text { Tegangan izin tekan } & : 0,45 \mathrm{f}^{\prime} \mathrm{c} & =0,45 \times 60 & =27 \mathrm{MPa} \\ \text { Tegangan izin tarik } & : 0,5 . \sqrt{ }\left(\mathrm{f}^{\prime} \mathrm{c}\right) & =0,5 \times \sqrt{60} & =3,87 \mathrm{MPa}\end{array}$

\section{METODE PENELITIAN}

Penelitian ini dilakukan berdasarkan hasil analisis dengan bantuan program MIDAS CIVIL. Dalam melaksanakan analisis, langkah-langkah yang dilakukan oleh penulis digambarkan melalui diagram alir penelitian seperti pada Gambar 2. 


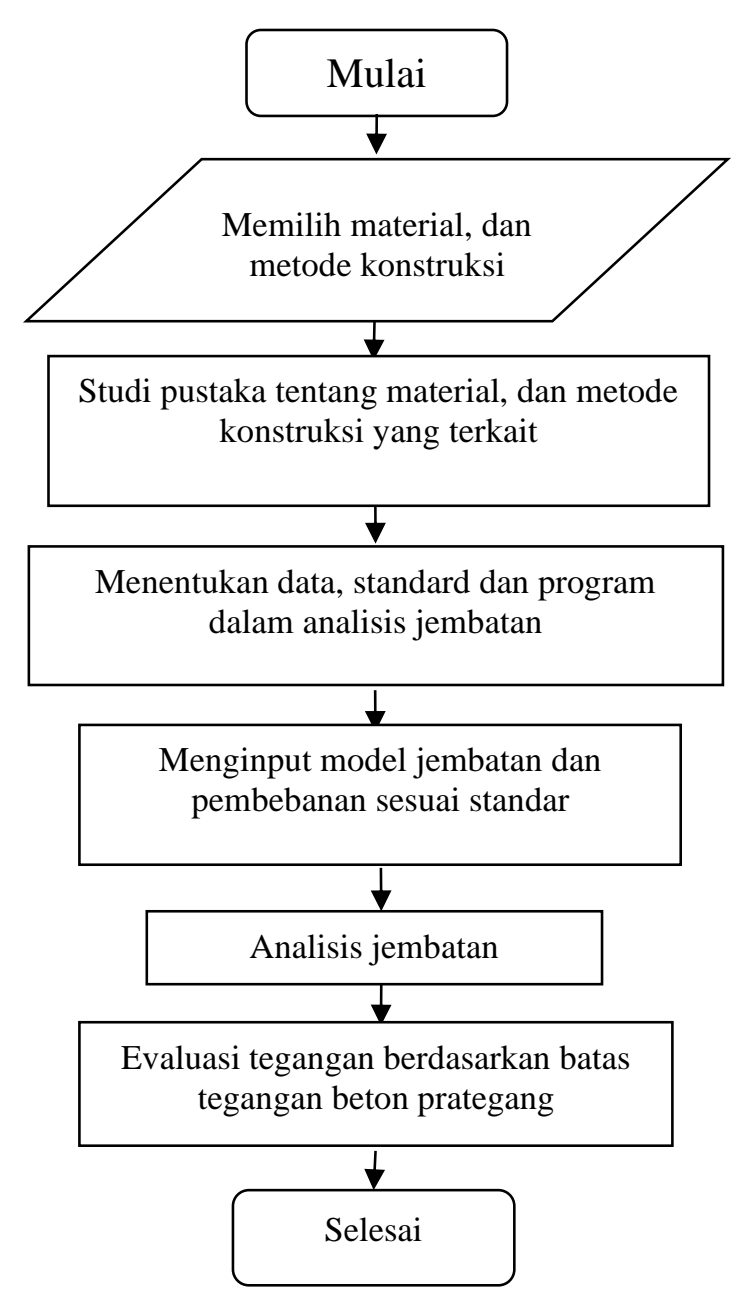

Gambar 2. Diagram alir penelitian

\section{Studi pustaka}

Penelitian dimulai dengan mengumpulkan teori untuk analisis jembatan box girder dengan metode balanced cantilever berupa buku, jurnal, penelitian.

\section{Data jembatan dan analisis dengan program MIDAS CIVIL}

Analisis dengan program MIDAS CIVIL dilakukan untuk mengetahui hasil tegangan pada jembatan. Langkah pertama yang dilakukan adalah memilih wizard sesuai dengan metode yang dianalisis yaitu FCM ( Free Cantilever Method ). Setelah itu, masukkan seluruh data jembatan berupa metode pembuatan beton, umur beton, yang dapat dilihat pada Gambar 3 dan Gambar 4. Selain itu, data material, pier, dan strand jembatan yang dimasukkan sebagai berikut :

- Mutu Beton $=60 \mathrm{MPa}$

- Mutu Baja = A416-270

- Ukuran Pier $\quad=4 \mathrm{~m} \times 4 \mathrm{~m}$

- Jumlah Strand $=12$

- Diameter Strand $=15,2 \mathrm{~mm}$ 


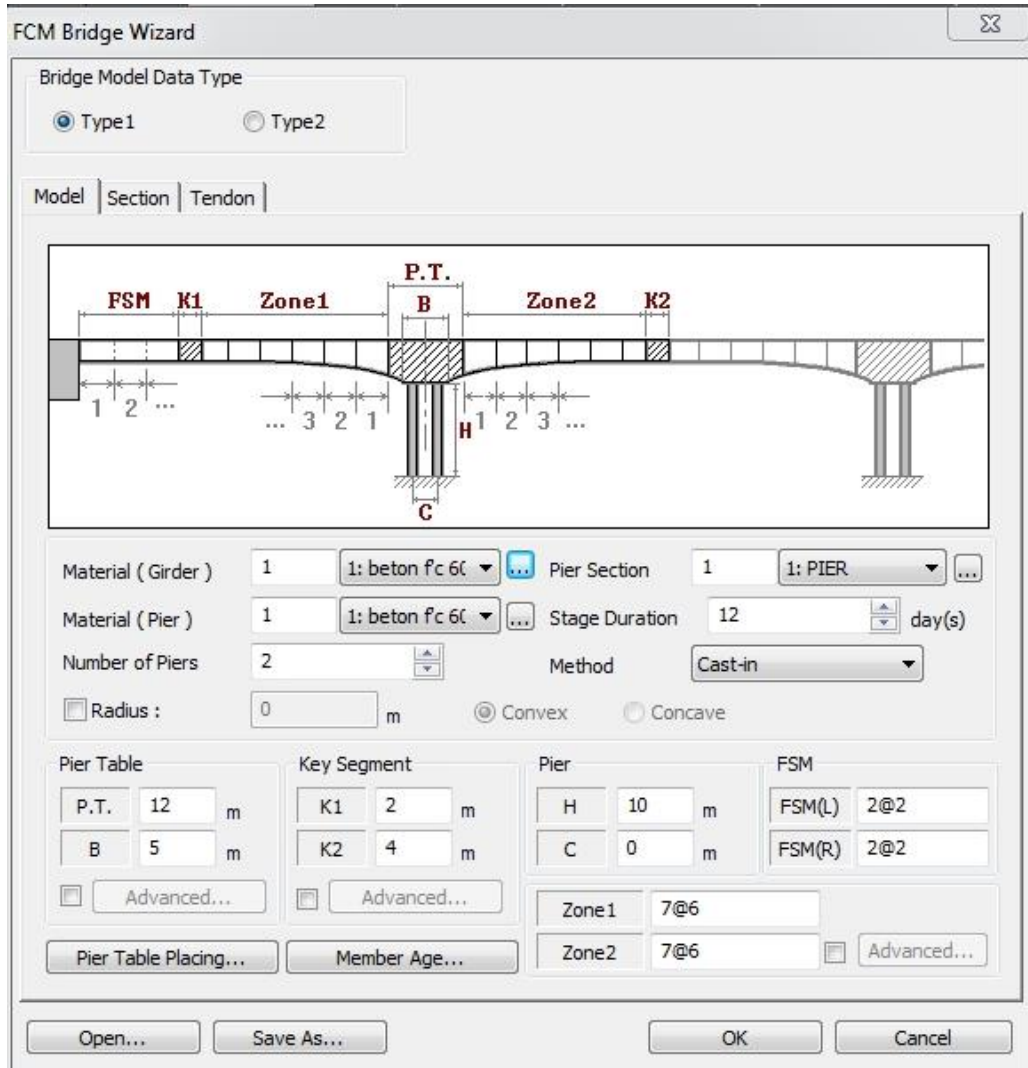

Gambar 3. Model jembatan

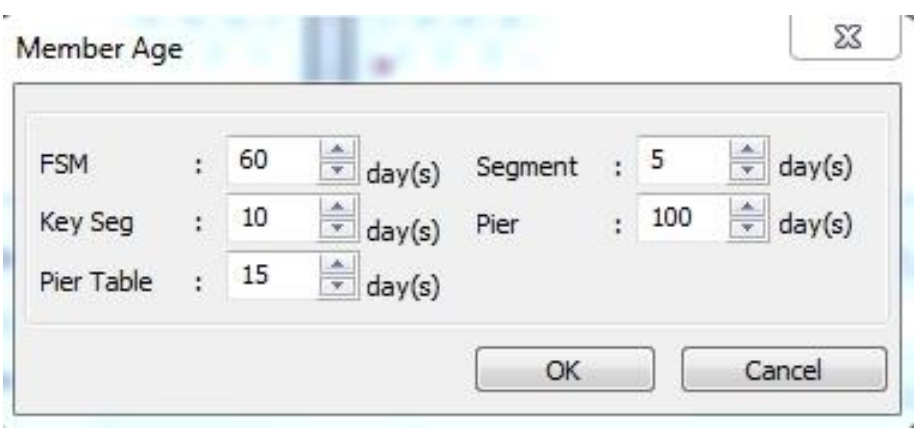

Gambar 4. Member age 
Selain data jembatan dan umur beton, hal penting yang harus diinput pada aplikasi MIDAS CIVIL yaitu ukuran box girder di atas pier table dan ukuran box girder saat berada di closure section, dan letak tendon yang dapat dilihat pada Gambar 5 sampai Gambar 7. Hal tersebut yang akan sangat menentukan tegangan pada analisis.

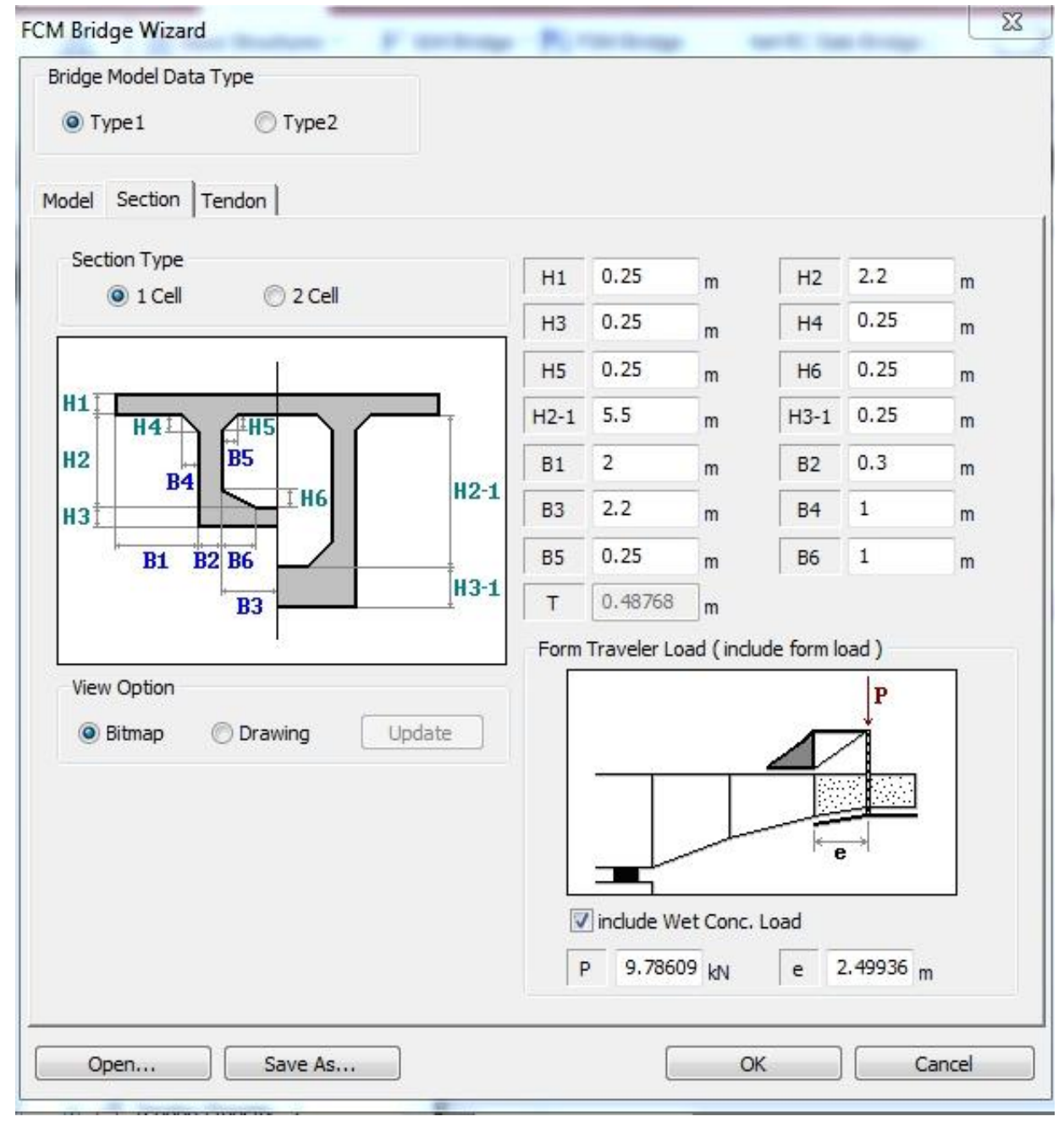

Gambar 5. Section box girder 


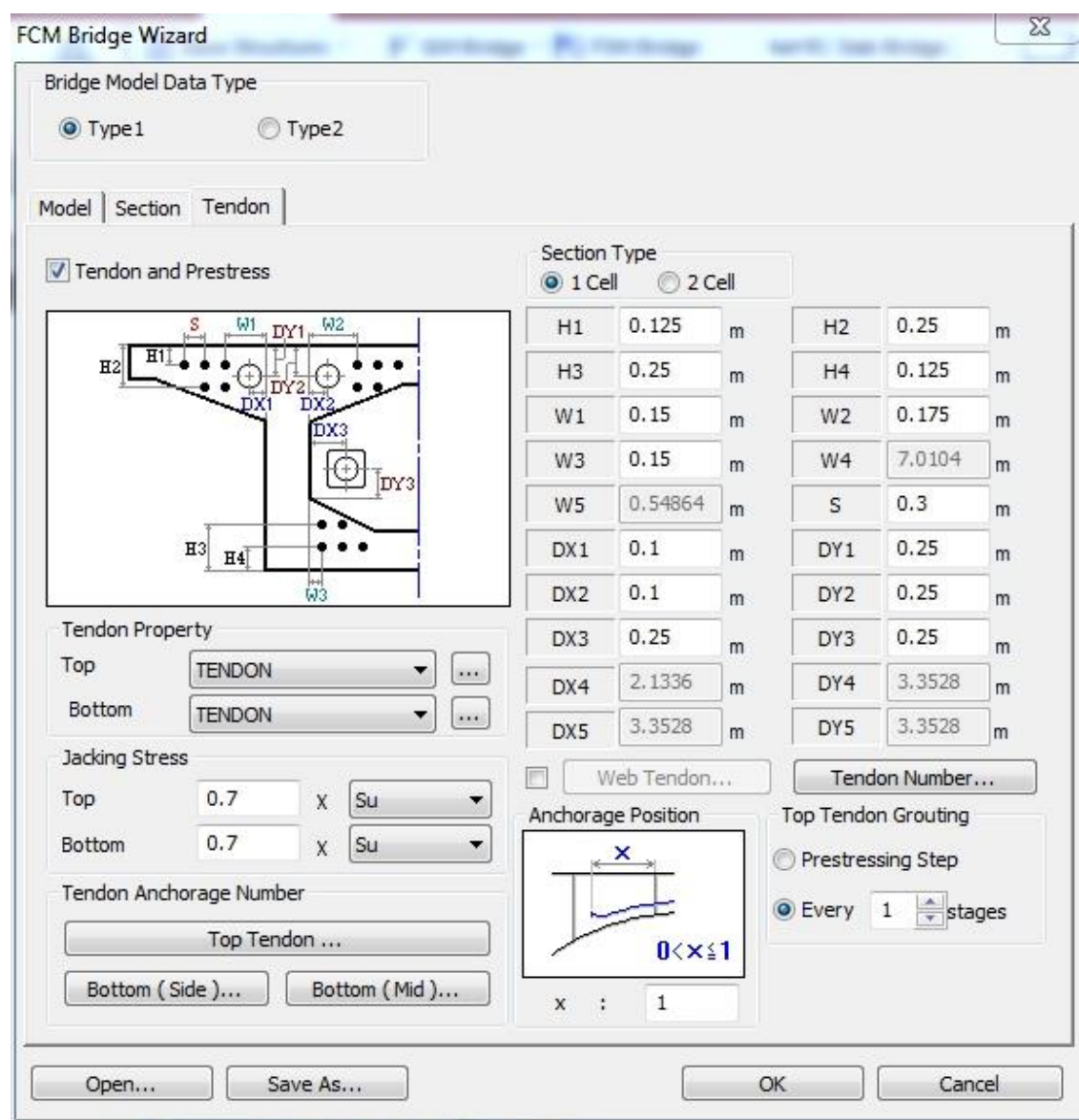

Gambar 6. Letak tendon

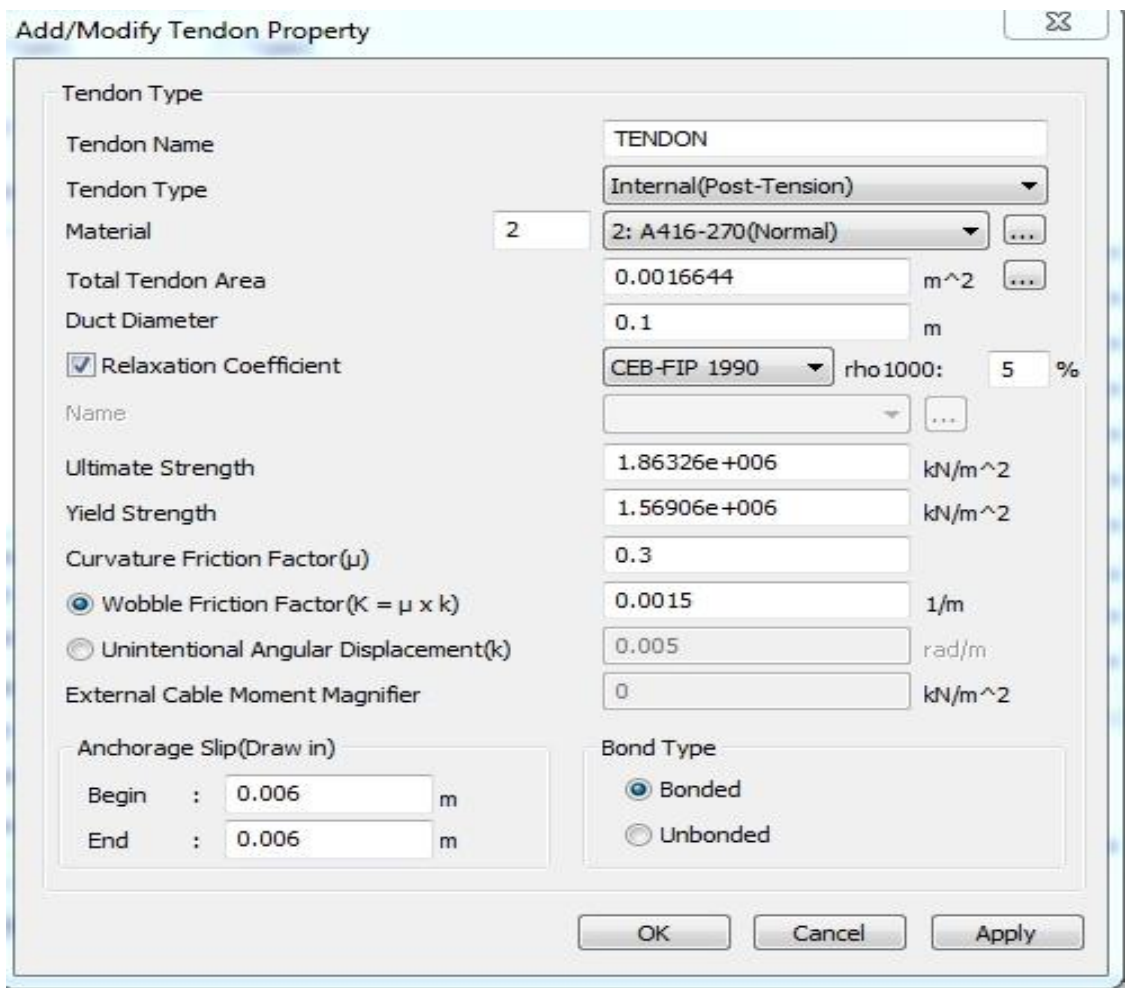

Gambar 7. Properti tendon 


\section{Creep dan shrinkage}

Dalam analisis jembatan beton prategang box girder dengan metode balanced cantilever ini memperhitungkan efek dari creep dan shrinkage dalam 1000 hari setelah konstruksi selesai dibangun. Langkah pertama dalam mengatur creep dan shrinkage adalah melakukan Add Time Dependent Material yang disajikan pada Gambar 8 dan Gambar 10. Untuk mengatur creep dan shrinkage juga perlu diatur Change Material dan Material Link ( hanya pada beton ).

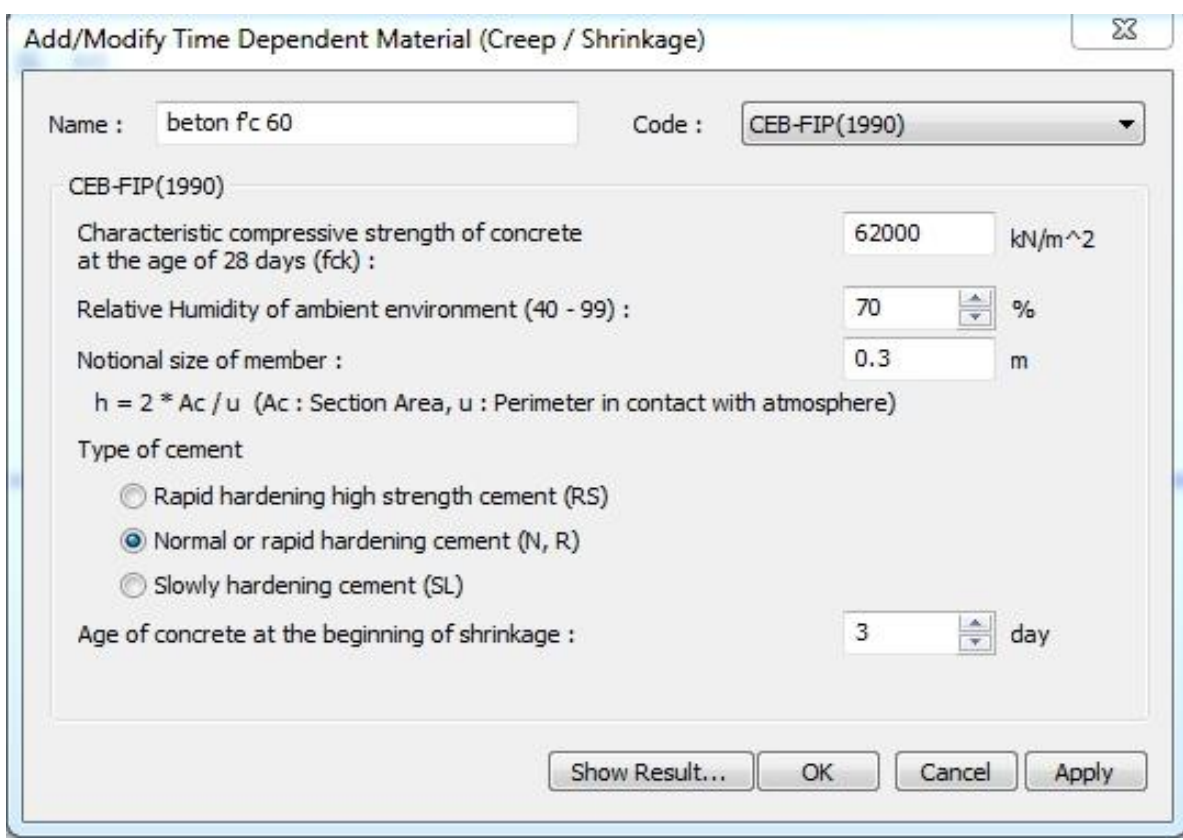

Gambar 8. Creep / shrinkage

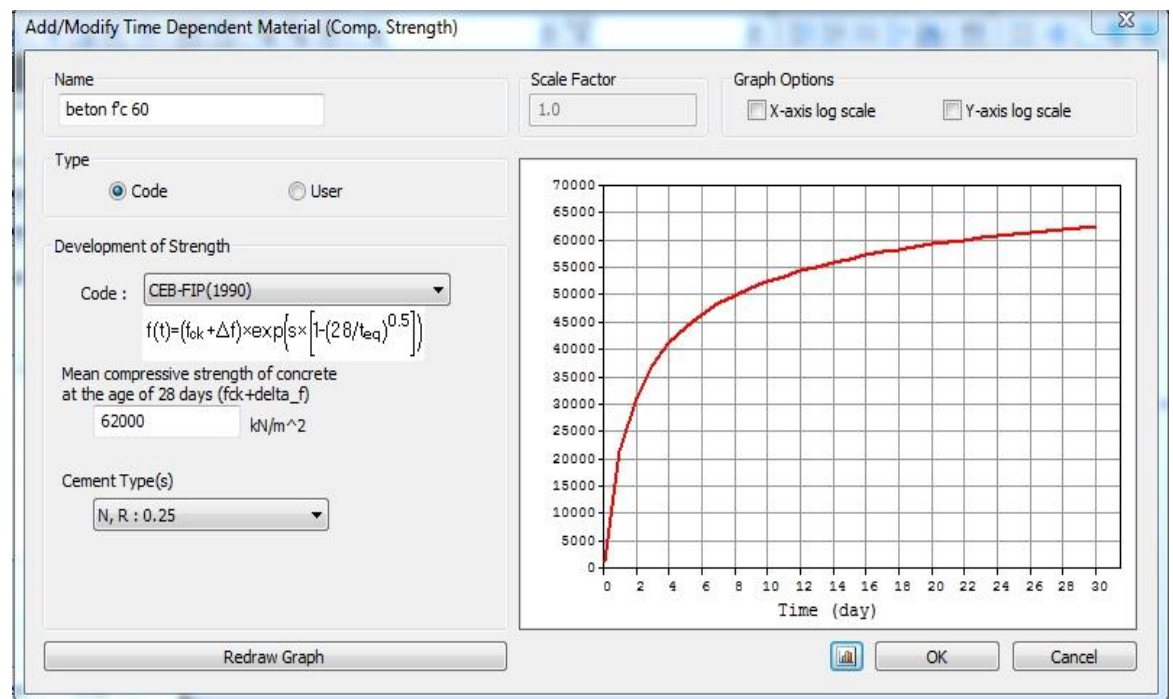

Gambar 9. Comp. Strength 


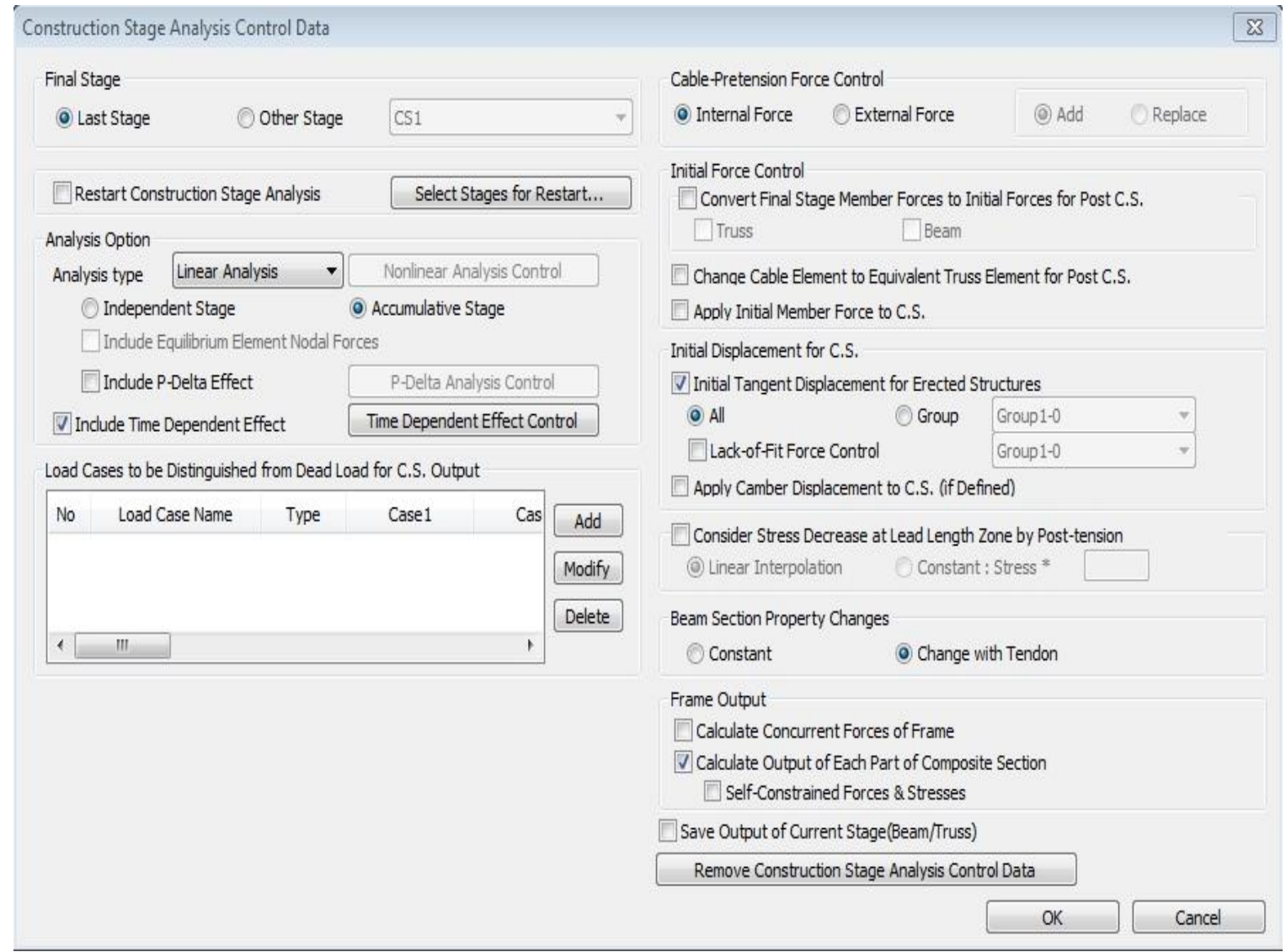

Gambar 10. Construction stage analysis

\section{Input beban}

Pembebanan yang diperhitungkan dalam analisis ini adalah berat sendiri, SDL ( element load), BTR ( element load ), dan BGT ( Nodal Load). Pembebanan mengacu pada SNI 1725 : 2016. Sesuai dengan data yang ditentukan yaitu ketebalan SDL sebesar $30 \mathrm{~mm}$, jenis SDL yang digunakan adalah beton aspal, lebar jembatan 9m, panjang total jembatan $200 \mathrm{~m}$, maka dihasilkan SDL sebesar $5.94 \mathrm{KN} / \mathrm{m}$, beban BTR sebesar $46.575 \mathrm{KN} / \mathrm{m}$, beban BGT sebesar 441 KN. Berdasarkan SNI 1725:2016, pembebanan BTR dan BGT dilakukan dalam 3 kombinasi.

- Kombinasi yang ke-1 disajikan pada Gambar 11 dan Gambar 12.

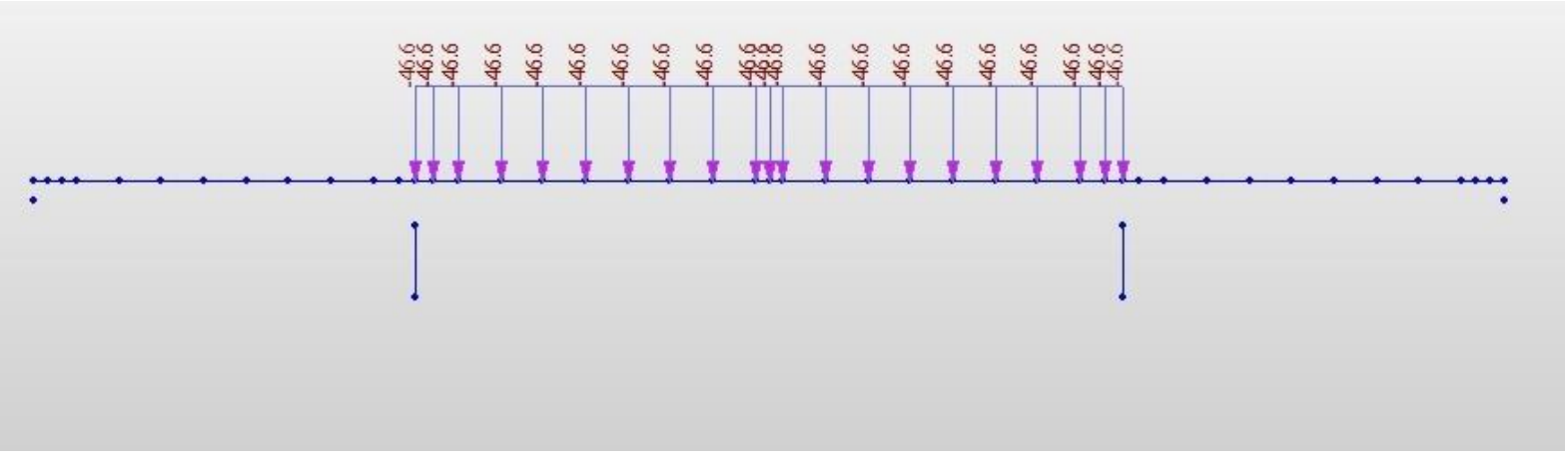

Gambar 11. Beban BTR kombinasi 1 


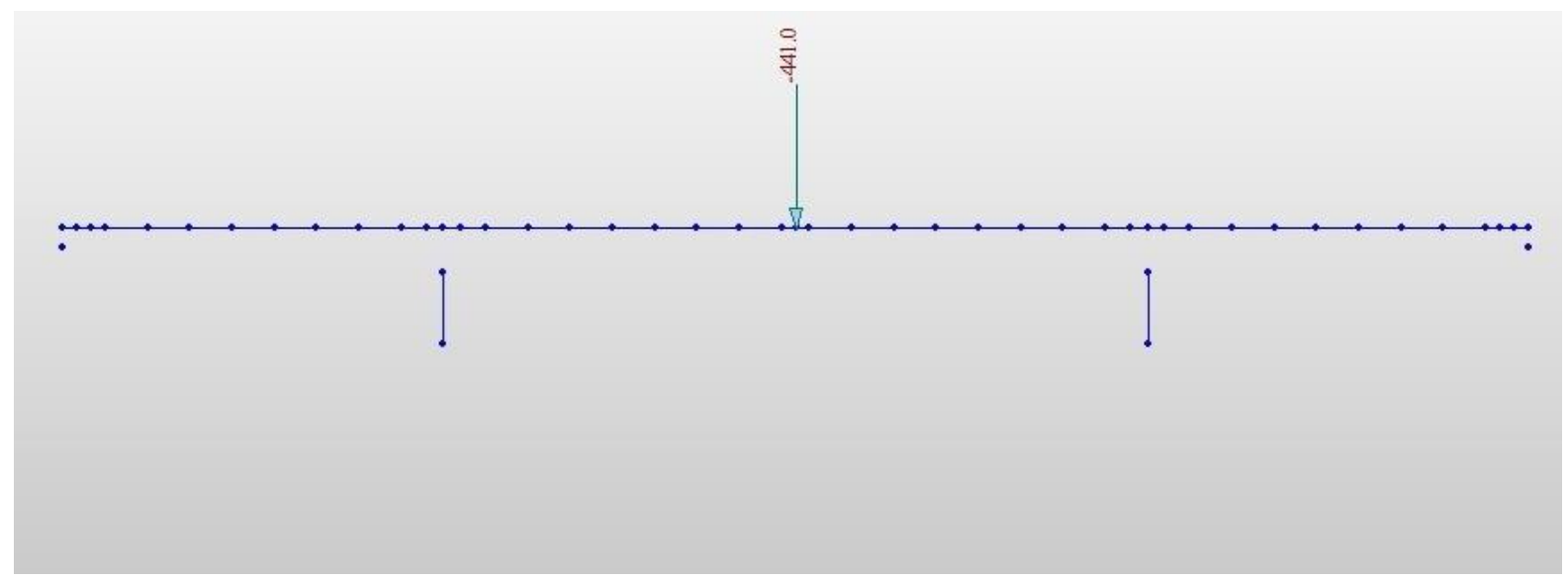

Gambar 12. Beban BGT kombinasi 1

- Kombinasi ke-2 dapat dilihat pada Gambar 13 dan Gambar 14.

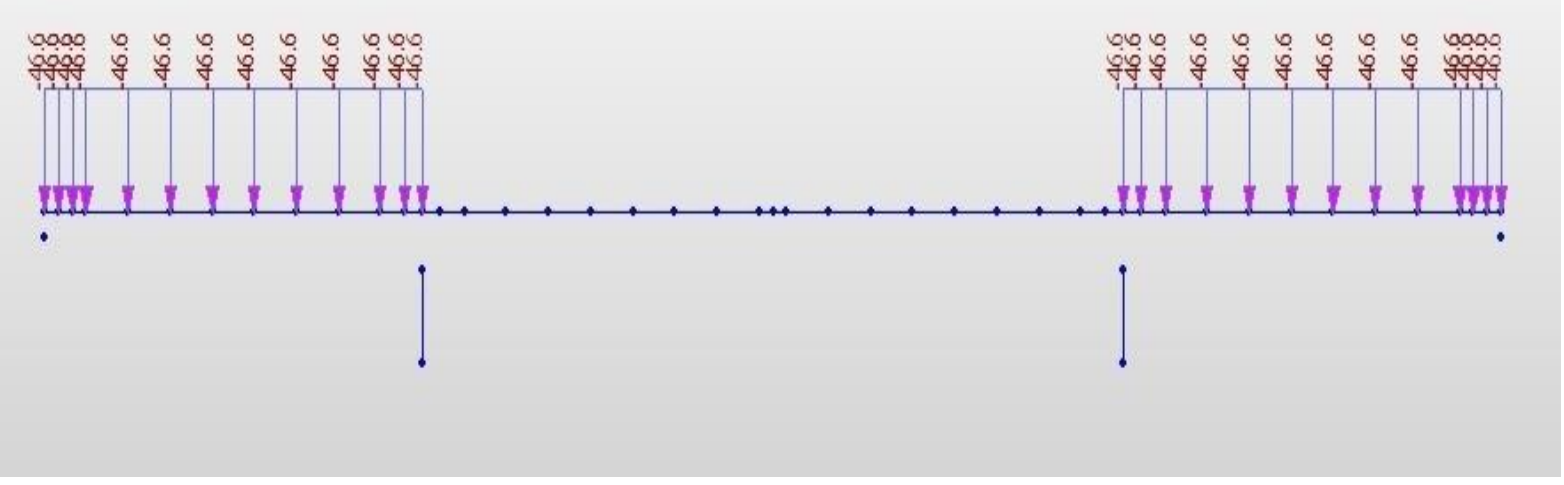

Gambar 13. Beban BTR kombinasi 2

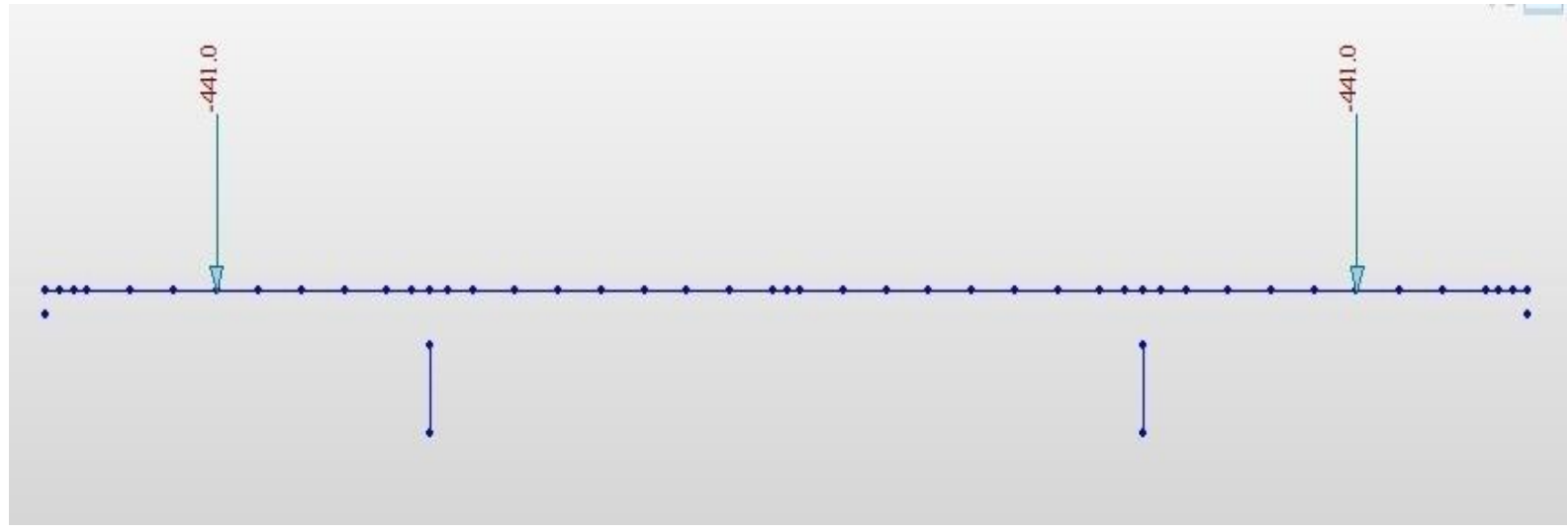

Gambar 14. Beban BGT kombinasi 2 
- $\quad$ Kombinasi ke-3 dapat dilihat pada Gambar 15 dan Gambar 16.

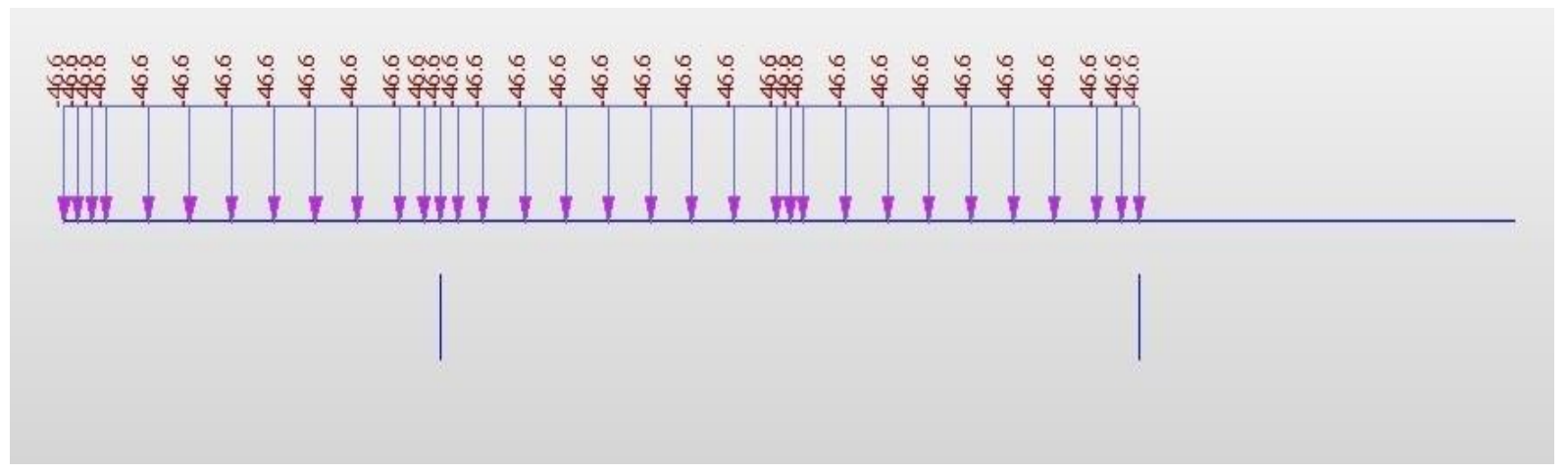

Gambar 15. Beban BTR kombinasi 3

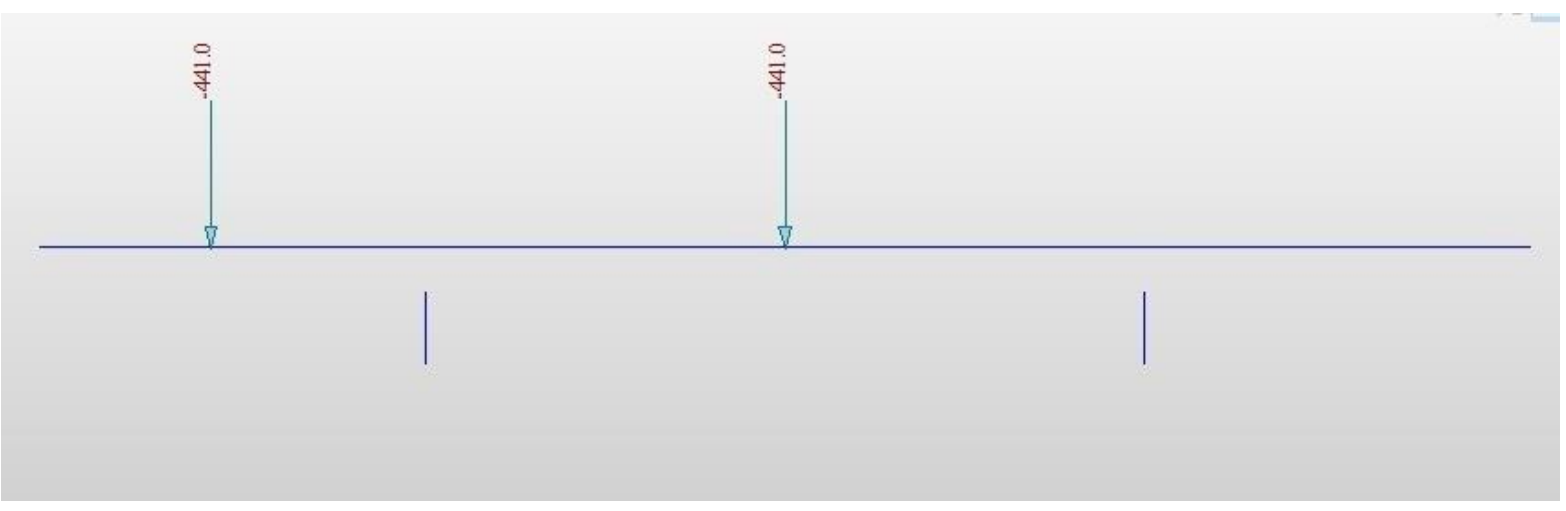

Gambar 16. Beban BGT kombinasi 3

\section{Analisis}

Langkah terakhir adalah melakukan analisis yang dapat dilakukan dengan perform analysis. Pada program MIDAS CIVIL, kombinasi dari pembebanan dimasukkan setelah melakukan analisis. Kombinasi dari pembebanan masih dalam kondisi service dengan faktor 1 kecuali BTR karena ada faktor impact sebesar 30\%. Kombinasi yang digunakan untuk mencari tegangan dengan mempertimbangkan beban SDL, BTR, BGT, creep dan shrinakage adalah dead load, tendon primary, tendon secondary, SDL, BTR, BGT, creep secondary, shrinkage secondary.

\section{HASIL DAN PEMBAHASAN}

Hasil tegangan dianalisis dari construction stage 1 sampai 11 dan 1000 hari setelah konstruksi selesai dengan kombinasi yang telah dicantumkan saat analisis. Pada tendon bagian atas, setiap tahap konstruksi dibutuhkan 2 tendon untuk menjaga keseimbangan struktur kecuali pada tahap terakhir yang membutuhkan 4 tendon pada bagian atas, sehingga total tendon bagian atas menjadi 36 tendon. Pada tendon bagian bawah digunakan di tengah kantilever dan di ujung jembatan hanya membutuhkan 1 tendon setiap 1 segmen dengan jumlah total masing - masing adalah 4 tendon. Untuk hasil pemodelan akhir beserta letak - letak tendon dapat dilihat pada Gambar 17 ( Not To Scale ).

Hasil analisis yang didapatkan adalah tegangan dari jembatan beton prategang box girder dengan metode balanced cantilever. Pada tahap konstruksi, tegangan tarik maksimum yang dihasilkan adalah 1,96 MPa dan tegangan tekan maksimum yang dihasilkan adalah -11,5 MPa. Pada saat konstruksi selesai, hasil tegangan tersebut juga masih memenuhi persyaratan dari beton prategang dengan tarik maksimal yang dihasilkan adalah 3,23 MPa dan tekan maksimal yang dihasilkan adalah -15,4 MPa, sedangkan batas tegangan izin tekan beton prategang pada keadaan akhir setelah kehilangan prategang adalah -27 MPa dan batas tegangan izin tarik beton prategang pada keadaan akhir setelah kehilangan prategang adalah 3,87 MPa. Rangkuman hasil tegangan selama masa konstruksi dan setelah konstruksi dengan 3 kombinasi dapat dilihat di Tabel 1. 

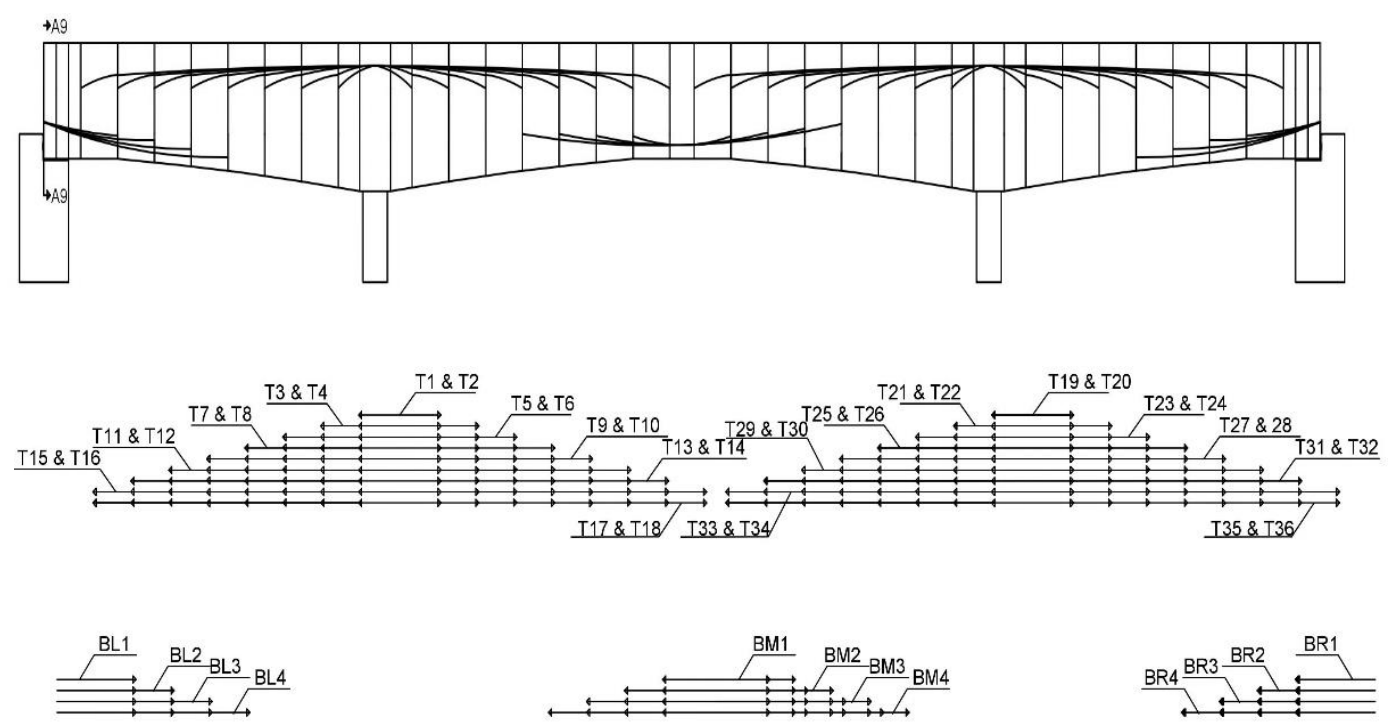

Gambar 17. Pemodelan akhir jembatan

Tabel 1. Summary tegangan

\begin{tabular}{ccccc}
\hline & $\begin{array}{c}\text { Serat Atas } \\
\text { Kiri } \\
\left(\mathbf{N} / \mathbf{m m}^{\wedge} \mathbf{2}\right)\end{array}$ & $\begin{array}{c}\text { Serat Atas } \\
\text { Kanan } \\
\left(\mathbf{N} / \mathbf{m m}^{\wedge} \mathbf{2}\right)\end{array}$ & $\begin{array}{c}\text { Serat Bawah } \\
\text { Kanan } \\
\left(\mathbf{N} / \mathbf{m m} \mathbf{2}^{\wedge}\right)\end{array}$ & $\begin{array}{c}\text { Serat Bawah } \\
\text { Kiri } \\
\left(\mathbf{N} / \mathbf{m m}^{\wedge} \mathbf{2}\right)\end{array}$ \\
\hline Max / Min Construction Stage & 1,96 & 1,96 & $-11,5$ & $-11,5$ \\
Max/Min Kombinasi 1 & 3,23 & 3,23 & $-15,4$ & $-15,4$ \\
Max/Min Kombinasi 2 & 1,88 & 1,88 & $-13,6$ & $-13,6$ \\
Max/Min Kombinasi 3 & 3,22 & 3,22 & $-15,1$ & $-15,1$ \\
\hline
\end{tabular}

\section{KESIMPULAN DAN SARAN}

Berdasarkan hasil analisis jembatan beton prategang box girder dengan metode balanced cantilever, maka didapatkan kesimpulan dan saran.

\section{Kesimpulan}

Berdasarkan hasil analisis, maka kesimpulan yang didapatkan adalah :

1. Terdapat 2 jenis tendon yaitu tendon primary dan secondary dimana primary adalah hasil yang terjadi pada struktur tertentu yaitu dari construction stage 1 sampai 11, sedangkan secondary adalah hasil yang terjadi pada struktur tak tentu yaitu dari construction stage 9 sampai construction stage 11.

2. Pada umumnya, konstruksi jembatan dengan metode balanced cantilever menggunakan box girder sebagai gelagar karena berat sendiri yang relatif ringan karena terdapat void pada bagian tengah box girder. Box girder juga dapat dibuat ukuran yang bervariasi dan mengecil pada closure segment untuk mengurangi berat sendiri dari jembatan.

3. Tegangan tarik dan tekan yang paling besar terjadi pada kombinasi 1 yaitu sebesar 3,23 MPa dan -15,4 MPa. Berdasarkan hasil tegangan maksimal tersebut, diketahui bahwa jembatan balanced cantilever dengan data yang telah ditentukan memenuhi dari syarat tegangan izin dari beton prategang.

\section{Saran}

Berdasarkan hasil analisis dari penulisan ini, terdapat beberapa hal yang harus diperhatikan dan diketahui agar analisis dapat berjalan dengan baik, maka saran yang dapat diberikan adalah :

1. Jumlah strand, diameter strand yang digunakan, dan jumlah tendon merupakan bagian yang sangat penting dalam mengatur tegangan tarik dan tekan yang terjadi pada saat masa konstruksi jembatan maupun setelah konstruksi selesai dibangun. 
2. Mengatur properti dari creep dan shrinkage tidak dapat dilakukan saat construction stage. Pengaturan tersebut hanya dapat dilakukan pada saat Base.

3. Pada saat memasukkan data ke MIDAS, ukuran menjadi hal yang sangat penting dan tidak boleh ada error dalam menginput data jembatan tersebut, terutama pada bagian section, karena terdapat 2 ketinggian box girder yang perlu diisi yaitu ketinggian box girder saat berada di pier table dan ketinggian box girder saat berada di bagian closure section.

4. Jika ingin memperhitungkan creep dan shrinkage, sebelum melakukan analisis, harus dipastikan bahwa time dependent effect telah diperhitungkan seperti pada gambar.

\section{DAFTAR PUSTAKA}

Hidayat, Irpan. Analisa Konstruksi Jembatan Cable Stayed Menggunakan Metode kantilever (Studi Kasus Jembatan Suramadu), 2011.

Rizkia, R.S. Analisis Perbandingan Kehilangan Prategang Akibat Metode Stressing Satu Arah dan Dua Arah pada Jembatan Beton Prategang, 2017.

Hernandez, S., Pablo Ouro, and Luis E. Romera. Optimization of PT in Cantilever Construction of Prestressed Concrete Bridges, 2014.

Badan Standardisasi Nasional. SNI 1725 : 2016. Pembebanan Untuk Jembatan, 2016.

Badan Standardisasi Nasional. SNI 2847 : 2013. Persyaratan Beton Struktural Untuk Bangunan Gedung, 2013. 
